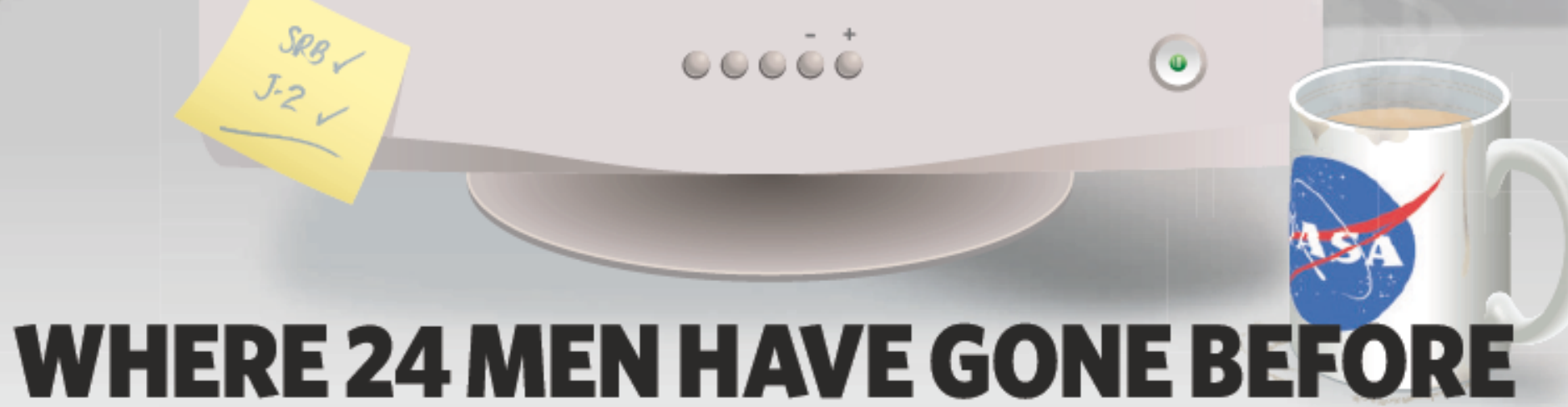

Three years ago, President George W. Bush told NASA to return American astronauts to the Moon. Geoff Brumfiel reports on how far they have got.

t's a drizzly afternoon in the middle of January, and a trickle of tourists is visiting the Smithsonian's Air and Space Museum in downtown Washington DC. Ambling around the museum's glass-and-steel atrium, the sightseers gravitate slowly towards the vintage space capsule at its centre.

Nine-year-old John Kalman and his greataunt Janet peer into the open door of the Apollo 11 command module Columbia, the craft in which the first men to walk on the Moon made their epic journey there and back. "That's awesome," exclaims the tow-headed boy as he gazes at panels from another age, jammed with hundreds of switches and indicator lights. "Look at how small it is," his aunt tells him. "It's not like the ones we use today, that's for sure."
True: today's astronauts fly in shuttles that were designed in the $1970 \mathrm{~s}$, rather than capsules from the 1960s. But for tomorrow's astronauts, Columbia is a glimpse of the future as well as the past. Under the agency's new Vision for Space Exploration, a somewhat larger craft, very similar to the Apollo capsule - 'Apollo on steroids', as it has been dubbed - will have replaced the shuttle in the role of carrying astronauts into orbit as early as 2014 . By around 2020, the agency plans to use these new capsules, along with other spacecraft, to return to the Moon and establish an outpost there. That sustained operation, officials hope, will provide a technical basis for a future mission to Mars.

'The vision', as it is often referred to within the agency, was first outlined by President George W. Bush on 14 January 2004. It marks a radical new direction for Americas human spaceflight programme. For the past two decades, NASA has been preoccupied with shuttling people to and from a low Earth orbit, mostly to visit the International Space Station. But the vision ${ }^{\alpha}$ is fundamentally different ${ }^{\prime}$, says Shana Dale, second in command at NASA. "It's about extending human presence on another world.

This extension, however, can't be built on the cheap; NASA's early estimates put the cost of the programme through to 2018 at around $\$ 104$ billion. To meet this bill, the agency is committed to grounding the space shuttle fleet in 2010 and cutting back its spending on the space station, which should be completed by then (see chart, page 477). It is also delaying and cancelling space-based science missions in astronomy, planetary science and Earth observation, as well 
as aeronautics programmes. Louis Friedman, executive director of the Planetary Society, a Pasadena-based educational organization in California that regularly criticizes this reallocation of resources, complains: ${ }^{\alpha}$ This is attacking exploration to supposedly pay for exploration."

NASA is thus under pressure from many fronts to make the vision more affordable. At the same time, it needs to be exciting enough to enthuse a population half of which was not born when a man last walked on the Moon. Yet the budgetary constraints mean that things need to be done in a way that seems less than fresh, using spacecraft that look like throwbacks, and making progress in seemingly undra-
"The key word in the current vision has to be sustainability." - Jeffrey Hoffman shuttle programme, according to John Logsdon, a space-policy expert at George Washington University in Washington DC, who sat on the investigation board. Just as disturbing was the banality for which the astronauts had died. Columbia had been on a mission to conduct some small experiments in microgravity, including a promotional test for a fragrance company. Untilitended in tragedy, the mission barely made local headlines in Houston. "We believed this was not an adequate vision to justify the risk of putting astronauts into space," Logsdon says. The board recommended a re-examination of NASA's entire rationale for human spaceflight.

In the late summer of 2003, NASA and the White House matic, incremental steps. The vision requires NASA to provide an inspiring future frontier while keeping things sustainable, sensible and safe.

\section{On wing and a prayer}

To understand the vision, you have to understand its origin. Business-as-usual at NASA did not come to a close with President Bush's speech in January 2004. It ended a year before. At 08:54 on 1 February 2003, engineers at mission control in Houston, Texas, were guiding another spacecraft called Columbia home from a routine, 16-day trip into low Earth orbit. Moving at 24 times the speed of sound, the shuttle had just begun a pre-programmed braking manoeuvre high over California, its wings sheathed in air heated to $1,300^{\circ} \mathrm{C}$. Suddenly, four temperature sensors on the left wing cut out. "You're telling me you lost them all at exactly the same time?" flight director LeRoy Cain asked his team. "No, not exactly," came the reply. "They were within probably four or five seconds of each other." The wing had been damaged, and now the superheated air had found its way inside; within minutes, Columbia and its crew of seven were a trail of debris falling out of the morning sky.

The damage was down to a flaw fundamental to the shuttle's design. During the launch, the leading edge of the wings was below the external fuel tank, so anything - in this case, insulating foam - that came off the tank stood a chance of damaging the surfaces most exposed during re-entry. The resultant accident investigation board chided NASA for not coming to grips with the problem earlier.

But the possibility of such engineering lapses was not the only problem with the

\section{programme that focused}

on robotic began to speak in earnest about the future. was promoting an ambitious programme that Marburger, the president's science adviser, and the White House Office of Management and

missions to the Moon and Mars and on human missions to the Moon. The debate ended in compromise: an aspirational nod towards Mars in the unspecified future, a near-term focus on the Moon in the 2010s, no more shuttle by the end of this decade. "I don't think anybody got everything they were looking for," Asner says.

\section{A giant leap}

When finally given voice, though, the vision's call to "extend human presence across the Solar System" certainly sounded satisfactorily sweeping in scope. "In the past 30 years, no human being has set foot on another world," Bush told a crowd at NASA's headquarters in Washington DC. "It is time for America to take the next steps." The crowd and almost everyone else familiar with NASA greeted the announcement enthusiastically, if only because the status quo had grown increasingly intolerable. ${ }^{\text {N }}$ NASA has been lacking a compelling vision for decades," says Keith Cowing, a former employee of NASA and co-author of New Moon Rising, a book about NASA's renewed plans for exploration. Before the vision, he says, "You could ask ten people what the goal of the agency was and you would get twelve answers". Now, NASA once again had a single purpose.

\section{Two Columbias: the iconic Apollomoonship (below) and the ill-fated shuttle.}


So far, so Apollo. But Bush made it clear that the vision was not going to involve an Apollo-era surge in NASA's budgets. The billions needed to complete the vision, it is claimed, will be the billions'saved' by not flying the shuttle and not spending on the space station. The budget for the vision will thus increase slowly, in synch with the decline of the existing programmes. The agency hopes to have its new 'crew exploration vehicle, the capsule called Orion, and the Ares-I rocket on which it will ride to orbit ready by 2014 . By 2020, it hopes to have built a lunar lander, and another, larger rocket, allowing missions to the surface of the Moon.

\section{Keeping up appearances}

The slow pace of the programme was, at the time, reflected in the president's budget, which initially recommended a modest $7 \%$ increase over five years for the US\$15-billion agency, but which didn't envisage an actual landing for 15 years or so. By contrast, Project Apollo went from a standing start to the Moon's Sea of Tranquillity in under a decade, but ramped up the NASA budget by $300 \%$ in the process.

This modest approach is the new way to do business at NASA. ${ }^{\alpha}$ The key word in the current vision has to be sustainability, says
Jeffrey Hoffman, professor of engineering at Massachusetts Institute of Technology (MIT) in Cambridge, and a former astronaut. Unlike Apollo, which spent enormous sums on a short-term programme to reach the Moon, the vision is supposed to be a sustained effort that will guide NASA well into the twenty-first century while not breaking the bank.

Perhaps no one element of the vision illustrates NASA's change in strategy better than its replacement for the space shuttle. In the 1980 s and $1990 \mathrm{~s}$, the agency toyed with various ideas for followon crafts that might fly into orbit unaided by booster rockets. Billions were spent, only to demonstrate that many more billions would be needed to build something that actually worked: a single-stage-to-orbit spacecraft is a very difficult proposition.

This time, says Scott Horowitz, who is in charge of developing Orion, "We're not depending on anytechnological mirades. It is a much more reasonable programme." The Orion capsule eschews wings and advanced propulsion, and depends entirely on disposable booster rockets. The result is not just operationally similar to Apollo's conical capsule on a cylindrical service module: it is essentially an enlarged carbon-copy that uses specific similarities to cut down the need for expensive novelty. The Ares-I rocket on which it will sit uses a solid-rocket booster just like the shuttle's as its first stage and an Apollo-era J-2 engine to power its second. The crew-escape system, which is also based on an Apollo-era system, can rapidly lift the capsule from the rocket if something goes wrong, making this a safer vehicle than the shuttle, at least during the launch.

Prudence is also guiding the agency's strategic planning, which now operates under what Dale describes as a "go-as-you-can-afford-to-pay approach", taking exploration forward in modest increments. After developing the Orion, which will cut its teeth taking crews to and from the space station, the programme will construct a lunar lander and a new heavy rocket - called Ares V - which will combine solid rockets and $\mathrm{J}-2$ engines to deliver 130 tonnes of payload to Earth orbit, as opposed to Ares I's 25 tonnes. That's enough to launch both the lunar lander and the engine needed to take Orion and its

\section{Along for the ride?}

NASA officials say that they don't want to go back to the Moon alone; they hope to get some help from international partners.

The space agency has already decided to take the lead in building the rockets, capsules and landers needed to get to the Moon's surface. But NASA hopes that it can get other contributions from foreign powers - perhaps a lunar rover or a module for the planned Moon base. "We're working with our international partners to figure out where they want to play in terms of exploration," says Shana Dale, the agency's deputy administrator.

Although NASA has started consulting with allies from around the world as part of its Global Exploration Strategy, not everyone is convinced by its overtures. "I personally feel a little bitdisappointed," says JeanMichel Desobeau of Arianespace, based in Paris. As an executive at Europe's largest commercial launch company, Desobeau thinks that NASA's decision to exclude foreign powers from its high-profile rocket-and capsuledevelopment programmes may lead to resentment among these countries. "Europe, Russia and China want to be more than just a subcontractor," hesays.

An even greater political obstacle orbits high above Earth. The International Space Station - the centrepiece of European, Russian and Japanese human spaceflight programmes - is still waiting for key modules to be delivered. NASA has committed to finishing the space station by 2010 , but intends to bring its involvement to an end after 2016, allowing it to focus its resources on the Moon. Keeping the spacestation supplied and ferrying crews back and forth will be a significant challenge to the remaining partners, of which only Russia has the capacity to fly humans into space.

The prospective American withdrawal has led to some wringing their hands, and could make other countries hesitant to join yet another NASA-led project.

It will take a little diplomacy to move the vision, says Roger

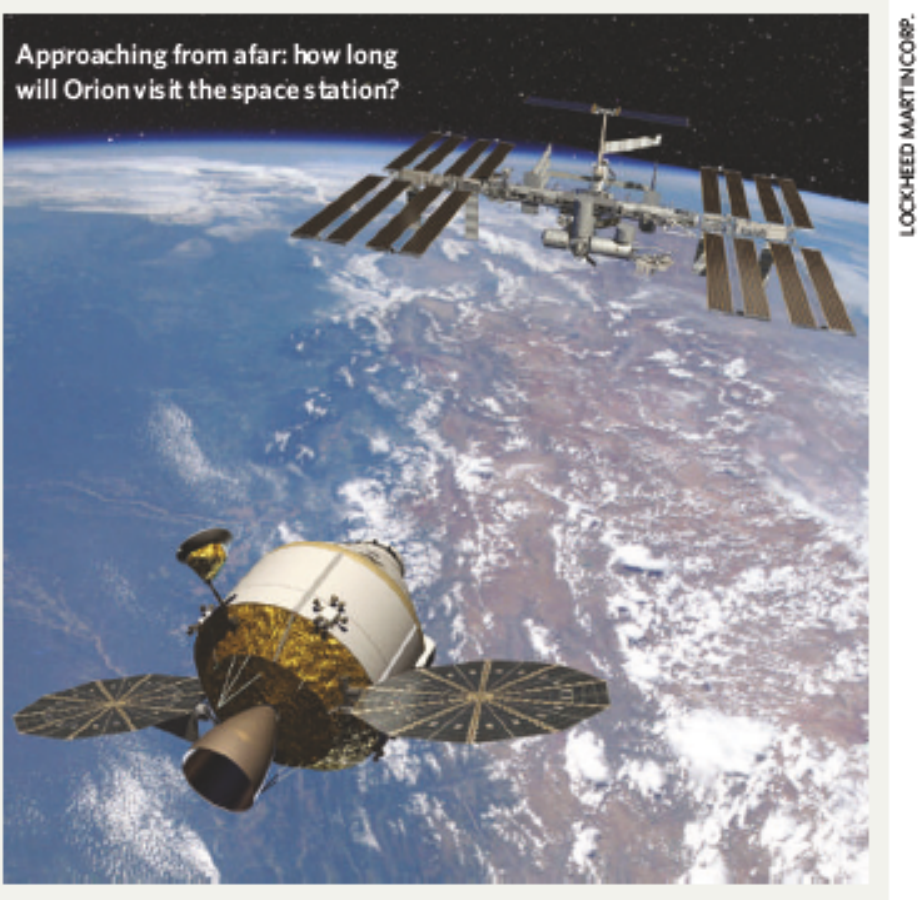

Bland ford of Stanford University in California. Blandford believes that, just like modern particle accelerators and fusion machines, a programme as ambitious as the vision requires collaboration. "Everybody has to band together," he says. "The only way that any of this makes sense economically is as a gobal enterprise." 


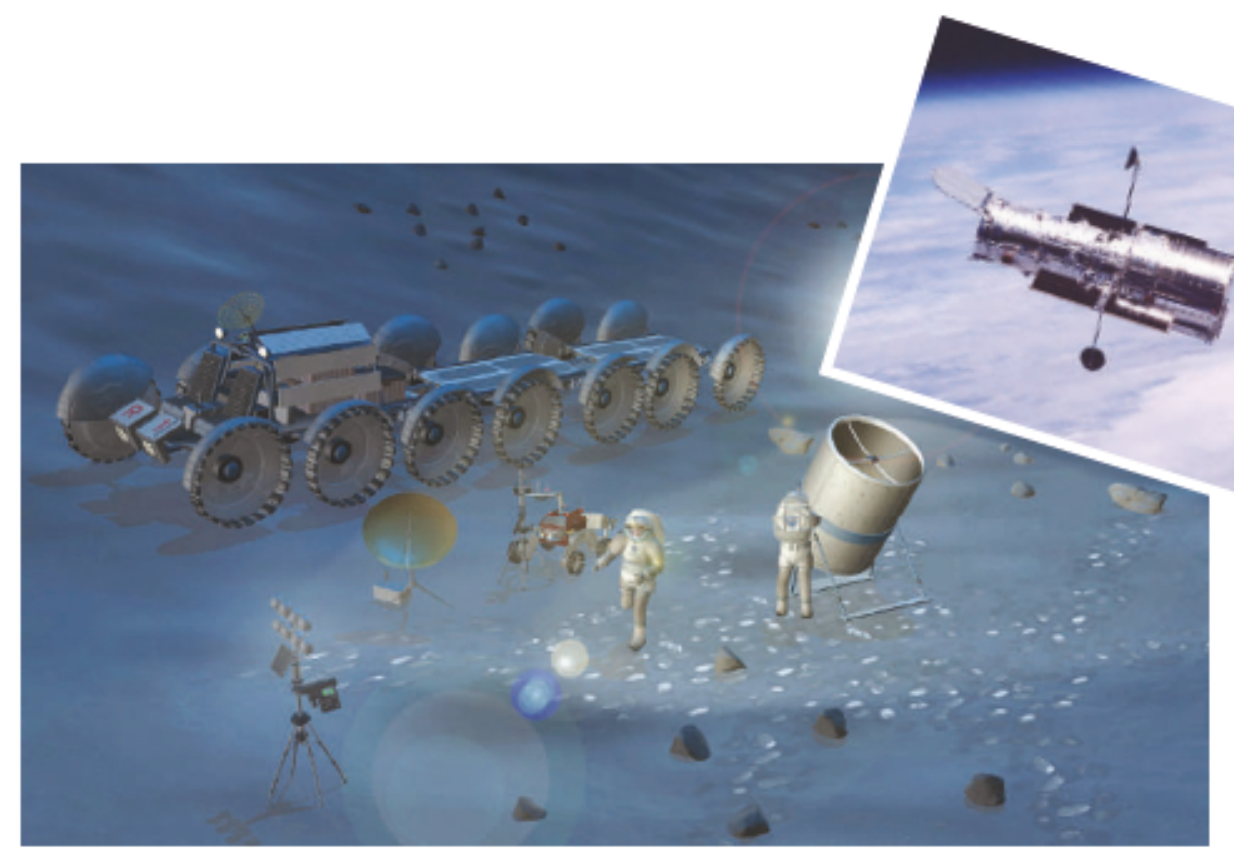

Eyes up: will telescopes on the Moon live out the legacy of the Hubble telescope (inset)?

accompanying lander from orbit round the Earth to orbit round the Moon. The difference from the 1960's approach is that Apollo launched its lander and command modules on a single Saturn V rocket; by launching Orion on one rocket and the lunar lander and transfer stage on a second, then having them dock in Earth orbit, the vision architecture allows larger crews and payloads.

\section{Short breaks}

At first, astronauts will use the lander/Orion combo for week-long trips to the Moon of the sort undertaken by the later Apollo missions. Gradually, the agency will build up resources for a permanently occupied base at one of the Moon's poles that will be visited by mission after mission. It is hoped that the outpost will give engineers experience in supporting humans on other worlds, eventually paving the way for a much more ambitious expedition to the surface of Mars. Rather than setting hard dates for completing each stage of the vision, NASA will adjust its plans to match each year's budget.

The vision's fiscal conservatism helped it win the imprimatur of Congress, which passed legislation to support it in 2005. But not all of its money-saving strategies have been popular with lawmakers. In August, NASA administrator Michael Griffin, who replaced O'Keefe in 2005, awarded the crew capsule contract to Lockheed Martin in Bethesda, Maryland, before the design had been reviewed fully. The move, says Horowitz, helped to cut costs by allowing NASA to fund one development team, rather than working with a pair of competing designs. But awarding a contract before the final design and cost had been fully assessed drew criticism. "Congress has to keep a keen and constant eye on the project," warned Sherwood Boehlert, the former Republican chair of the House of Representatives Science and Technology Committee in a hearing last September. "Neither the agency nor the nation can afford another space station - a project that, for all its technical magnificence, has seen its costs balloon while its capabilities shrank to near the vanishing point."

Already the agency is facing some tough financial choices. The $7 \%$ over five years that President Bush spoke of did not end up in his budgets; in the White House's budget request for fiscal year 2007, produced last January, NASA's budget was kept essentially flat. "I would give Bush an 'A' for vision and a 'C-' for followthrough," Cowing says. And Congress, which has the final say, has allowed the agency less than the president asked for every year since the vision was first proposed. Adding to its woes have been the unexpected hundreds of millions of dollars

\section{THE COST OF A VISION}

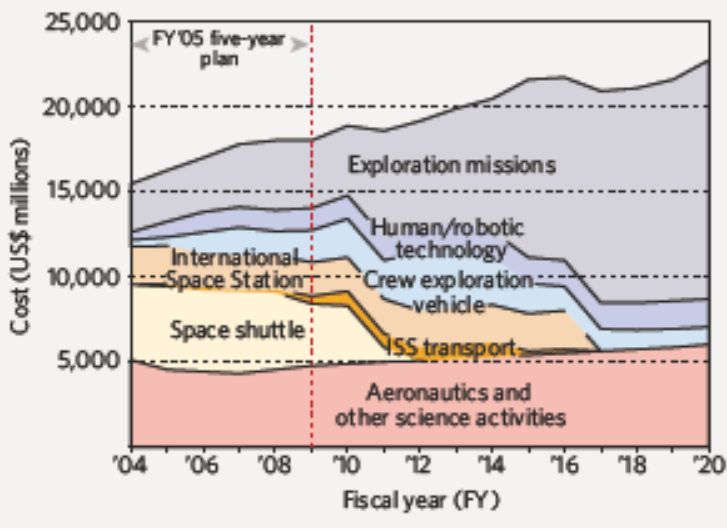

spent on returning the shuttle to flight and repairs to facilities dam- 2 aged by 2005 's Hurricane Katrina. NASA also has a service mission to the Hubble Space Telescope back on the books, with all its attendant costs. And this year, a breakdown in the congressional budget process is likely to leave the agency about half-a-billion dollars short of where it wanted to be (see Nature 445, 130; 2007).

\section{Chopping and changing}

To offset a lack of overall growth in NASA's funding, the president's budget for 2007 called for its astrobiology programmes to be slashed by $50 \%$ and for an $18 \%$ cut in its $\$ 854$-million aeronautics budget. Several Earth-observing satellites, notably the Global Precipitation Mission, have been delayed. Longed-for science flagships such as missions to obtain samples from the surface of Mars and to study Earthlike planets around nearby stars have been deferred indefinitely. Friedman argues that similarly inspiring science missions, such as the Hubble telescope and the Mars Exploration Rovers, have been the bedrock of public support for NASA. Cancelling their natural heirs, he says, will erode enthusiasm for space: "You can't maintain public support on just a rocket programme."

Horowitz counters that the exploration programme will open up new areas of research to scientists, especially on the surface of the Moon. Plans call for astronauts to be able to access to any part of the Moon that scientists might want to visit, and NASA is holding workshops to find out the sorts of projects they might want to do there. The bottom line, he says, is that the exploration will fund science "even though you don't see it in dollars in the science budget line".

And some scientists are enthused about the prospect of getting to work on the lunar surface. "There's a lot that we didn't learn about the Moon from the Apollo missions," says Paul Spudis, a geologist at Johns Hopkins University's Applied Physics Laboratory in Laurel, Maryland. Although models show that the Moon was probably formed by Earth's collision with another body the size of Mars, many details about this originating catadysm remain unknown. Studying materials near the base of the Moon and comparing that information with remote sensing data from all around it will teach scientists a great deal about the specific circumstances surrounding the Moon's creation and evolution.

But most researchers, including some who are enthused bylunar exploration, 
